\title{
Effect of Carotenoid Supplemented Formula on Carotenoid Bioaccumulation in Tissues of Infant Rhesus Macaques: A Pilot Study Focused on Lutein
}

\author{
Sookyoung Jeon ${ }^{1}$, Martha Neuringer ${ }^{2}$, Emily E. Johnson ${ }^{2}$, Matthew J. Kuchan ${ }^{3}$, \\ Suzette L. Pereira ${ }^{3}$, Elizabeth J. Johnson ${ }^{4}$ and John W. Erdman Jr. ${ }^{1,5, *}$ \\ 1 Division of Nutritional Sciences, University of Illinois at Urbana-Champaign, Urbana, IL 61801, USA; \\ sjeon17@illinois.edu \\ 2 Oregon National Primate Research Center, Oregon Health and Science University, Beaverton, OR 97239, \\ USA; neuringe@ohsu.edu (M.N.); johnsemi@ohsu.edu (E.E.J.) \\ 3 Abbott Nutrition, Columbus, OH 43215, USA; matthew.kuchan@abbott.com (M.J.K.); \\ suzette.pereira@abbott.com (S.L.P.) \\ 4 Jean Mayer United States Department of Agriculture Human Nutrition Research Center on Aging, \\ Tufts University, Boston, MA 02111, USA; Elizabeth.Johnson@tufts.edu \\ 5 Department of Food Science and Human Nutrition, University of Illinois at Urbana-Champaign, Urbana, \\ IL 61801, USA \\ * Correspondence: jwerdman@illinois.edu; Tel.: +1-217-333-2527
}

Received: 9 December 2016; Accepted: 4 January 2017; Published: 10 January 2017

\begin{abstract}
Lutein is the predominant carotenoid in the developing primate brain and retina, and may have important functional roles. However, its bioaccumulation pattern during early development is not understood. In this pilot study, we investigated whether carotenoid supplementation of infant formula enhanced lutein tissue deposition in infant rhesus macaques. Monkeys were initially breastfed; from 1 to 3 months of age they were fed either a formula supplemented with lutein, zeaxanthin, $\beta$-carotene and lycopene, or a control formula with low levels of these carotenoids, for 4 months ( $n=2$ /group). All samples were analyzed by high pressure liquid chromatography (HPLC). Final serum lutein in the supplemented group was 5 times higher than in the unsupplemented group. All brain regions examined showed a selective increase in lutein deposition in the supplemented infants. Lutein differentially accumulated across brain regions, with highest amounts in occipital cortex in both groups. $\beta$-carotene accumulated, but zeaxanthin and lycopene were undetectable in any brain region. Supplemented infants had higher lutein concentrations in peripheral retina but not in macular retina. Among adipose sites, abdominal subcutaneous adipose tissue exhibited the highest lutein level and was 3-fold higher in the supplemented infants. The supplemented formula enhanced carotenoid deposition in several other tissues. In rhesus infants, increased intake of carotenoids from formula enhanced their deposition in serum and numerous tissues and selectively increased lutein in multiple brain regions.
\end{abstract}

Keywords: carotenoids; lutein; bioaccumulation; brain; retina; Rhesus Macaques; infants; formula

\section{Introduction}

Lutein, a yellow xanthophyll pigment, cannot be endogenously synthesized. Therefore, humans depend on dietary sources of this carotenoid, especially from green leafy vegetables, like kale, spinach, and broccoli [1]. Lutein and zeaxanthin are uniquely concentrated in the fovea of the primate retina and are known for their beneficial roles in eye health as antioxidants and blue light filters [2]. Intake of lutein and zeaxanthin from dietary sources is associated with a decreased risk of age-related macular degeneration (AMD), a leading cause of irreversible blindness in adults [3]. In addition to lutein's 
impact on eye health, a recent meta-analysis reported that higher lutein consumption and higher lutein blood levels were associated with a lower risk of coronary heart disease, stroke, and metabolic syndrome [4]. Furthermore, lutein is increasingly being implicated as having a role in cognitive function [5]. Such a role is supported by recent studies showing that lutein was selectively deposited in the brains of infant and older adults [6,7]; that lutein supplementation was associated with improved cognitive function in older female subjects [8]; and that macular pigment optical density (MPOD) was related to cognitive function in older adults [9-11].

Emerging evidence suggests that lutein plays important roles in early human development. Lutein was the most abundant carotenoid in cord plasma, and its concentration was strongly correlated with maternal plasma lutein, suggesting a possible role of lutein in the neonatal period [12]. Lutein is the predominant carotenoid in brain in both infants and older adults, and its preferential accumulation in the infant brain implies a possible role in central nervous system development $[5,13]$. In a metabolomic study, lutein concentrations in infant brain were significantly correlated with neurotransmitters that are involved in neuronal proliferation and maturation, neurite outgrowth and synapse formation [14]. In addition, lutein administration in the first hours of life increased biological antioxidant potential and decreased oxidative stress [15]. Since breast milk or infant formula are the only dietary sources of lutein before solid food is introduced [13], it is critical to understand how dietary lutein relates to tissue bioaccumulation during early life.

Lutein is poorly absorbed and present in negligible levels in the retina and brain of most experimental animal models. Amongst non-human animals, only primates selectively accumulate lutein and zeaxanthin in their retina/macula and brain [16]. Li et al. recently suggested that this unique accumulation in primate retina is related to the inactivity of the primary lutein mammalian carotenoid cleavage enzyme, $\beta, \beta$-carotene $9^{\prime}, 10^{\prime}$-oxygenase (BCO2) [17] due to loss of an alternate splice site. On the other hand, other studies suggested that the activity of human BCO2 is conserved and dependent on subcellular localization [18,19]. Considering this unique metabolism of lutein in primates, the non-human primate is the most relevant animal model for investigating lutein's functional role in the eye and brain. In addition, lutein bioaccumulation patterns during the first few months of age are poorly understood, largely because human infant tissue samples are not readily available. Since lutein's unique pattern of accumulation can provide clues to its functional role in eyes and brain, we considered it important to describe lutein bioaccumulation patterns in developing rhesus macaques. Therefore, we investigated how bioaccumulation patterns are influenced by levels of carotenoids in infant formulas.

\section{Materials and Methods}

\subsection{Ethics Statement}

All procedures for this specific study were approved by the Institutional Animal Care and Use Committee of Oregon Health and Science University (OHSU IACUC Protocol IS3766) and carried out in accordance with the National Institutes of Health Guide for the Care and Use of Laboratory Animals.

\subsection{Animals and Diets}

Two male and two female rhesus monkeys (Macaca mulatta) were group-housed with their dams from birth until 1-3 months of age; the dams were fed Monkey Diet Jumbo 5037 (Lab Diet, St. Louis, MO, USA) supplemented with a variety of fresh fruits and vegetables. The infants were then weaned and formula-fed according to detailed protocols for nursery rearing at ONPRC. One male and one female, starting at 27 and 86 days old, respectively, were fed a formula (Similac ${ }^{\circledR}$ OptiGRO $^{\text {TM }}$, Abbott Laboratories, Abbott Park, IL, USA) supplemented with lutein, zeaxanthin, $\beta$-carotene, and lycopene, and one male and one female, starting at 63 and 26 days of age, respectively, were fed an unsupplemented formula with low levels of these carotenoids. The carotenoid profiles of the two formulas are provided in Table 1 and the characteristics of the subjects are described in Table 2. Upon 
weaning, infants were hand-fed if needed until able to self-feed, with feedings initially four times per day for the younger infants and then decreasing to three times per day at 60 days and older. Small amounts of supplemental solid foods low in carotenoids were provided daily to older infants. All infants were fed their respective formula for a duration of four months. The infants were socialized with infants of similar age and housed in cages with age-appropriate blankets, stuffed toys, and other enrichment devices. The infants' health and behavior was monitored daily by primate veterinarians as well as specialists in primate behavior and psychological well-being. The data reported here are part of a larger study of the effects of lutein supplementation on retinal and brain development.

Table 1. Carotenoid profiles of the infant formulas ${ }^{1}$.

\begin{tabular}{ccccccc}
\hline Formula Type & Lutein & Zeaxanthin & $\boldsymbol{\beta}$-Carotene & Lycopene & \multicolumn{1}{c}{$\boldsymbol{\beta}$-Cryptoxanthirx-Carotene } \\
\hline Supplemented formula (Similac) & 248 & 23 & 88 & 362 & ND $^{2}$ & ND $^{2}$ \\
Unsupplemented formula & 16 & ND & 32 & ND & ND & ND \\
\hline
\end{tabular}

${ }^{1}$ Data are expressed in $\mathrm{nmol} / \mathrm{L} ;{ }^{2} \mathrm{ND}$, not detected.

Table 2. Monkey characteristics.

\begin{tabular}{ccc}
\hline Group, Animal ID & Gender & Age (Days) at Enrollment \\
\hline Supplemented formula & & 27 \\
1 & Male & 86 \\
2 & Female & \\
\hline Unsupplemented formula & & 26 \\
3 & Female & 63 \\
\hline
\end{tabular}

\subsection{Plasma, Serum, and Tissue Collection}

Fasted $1 \mathrm{~mL}$ blood samples were collected in Ethylenediaminetetraacetic acid (EDTA) and processed to obtain plasma at baseline (before the first formula feeding) and after two and four weeks of formula feeding. After four months (133-135 days) of formula feeding, at ages 162 and 221 days for the supplemented group and 160 and 196 days for the unsupplemented group, infant monkeys were humanely euthanized by a veterinary pathologist under deep pentobarbital anesthesia, in accord with the recommendations of the Panel on Euthanasia of the American Veterinary Medical Association.

At the time of death, fasting blood samples were drawn and centrifuged at $800 \times g$ for $15 \mathrm{~min}$ to obtain serum. Tissues for carotenoid analysis were collected rapidly, placed in cryotubes and frozen in liquid nitrogen. From the brain, samples (approximately $0.5-1 \mathrm{~g}$ each) were dissected from prefrontal cortex, occipital cortex, superior temporal cortex, striatum, hippocampus and cerebellum. From each retina, $4 \mathrm{~mm}$ biopsy punches were used to obtain a macular sample centered on the fovea and samples of the peripheral retina; the vitreous was removed by blotting with filter paper, and the neural retina was gently dissected from the underlying retinal pigment epithelium and choroid.

\subsection{Carotenoid Analysis}

All extractions and analyses were performed under yellow light to prevent light-induced damage of carotenoids. All extracts were stored under argon at $-20^{\circ} \mathrm{C}$ for less than $48 \mathrm{~h}$ before high pressure liquid chromatography (HPLC) analysis.

\subsubsection{Formula Extraction for Carotenoids}

To $2 \mathrm{~mL}$ of formula was added $10 \mathrm{~mL} 5 \% \mathrm{KOH}(w / v$ in methanol) and the mixture was vortexed for $15 \mathrm{~s}$. Five $\mathrm{mL}$ of tetrahydrofuran (THF) was added and the mixture was vortexed for $1 \mathrm{~min}$. Ten $\mathrm{mL}$ of extraction solvent (dichloromethane/petroleum ether/hexane, 2:4:4) containing 0.005\% butylated hydroxytoluene (BHT) was added, vortexed for $1 \mathrm{~min}$, and centrifuged at $800 \times g$ for $15 \mathrm{~min}$. The upper 
organic layer was transferred into a test tube. To the bottom layer, $10 \mathrm{~mL}$ of extraction solvent was added and the extraction process was repeated one more time. The extract was pooled and evaporated under nitrogen. To the dried extract were added $3 \mathrm{~mL}$ deionized water and $3 \mathrm{~mL}$ ethanol. This mixture was vortexed for $2 \mathrm{~min}$, sonicated for $3 \mathrm{~min}$ and centrifuged at $800 \times g$ for $5 \mathrm{~min}$ at $4{ }^{\circ} \mathrm{C}$. The upper layer was transferred to a $12 \times 75 \mathrm{~mm}$ test tube and dried under nitrogen in a water bath $\left(40{ }^{\circ} \mathrm{C}\right)$. The dried extract was reconstituted with $50 \mu \mathrm{L}$ ethanol, vortexed, and sonicated for $30 \mathrm{~s}$. Twenty $\mu \mathrm{L}$ of the reconstituted extract was analyzed by HPLC using a semibore C 30 column [20].

\subsubsection{Plasma or Serum Extraction for Carotenoids}

Plasma or serum carotenoids were extracted as previously described [21]. Briefly, about $250 \mu \mathrm{L}$ sample was mixed with an equal volume of ethanol containing $0.1 \%$ BHT to precipitate protein and then vortexed for $30 \mathrm{~s}$. One $\mathrm{mL}$ hexane was added, vortexed, and centrifuged at $2400 \mathrm{rpm}$ at $4{ }^{\circ} \mathrm{C}$ (Centrifuge 5417R, Eppendorf, Hamburg, Germany) for $3 \mathrm{~min}$. The upper hexane layer was removed. The hexane extraction process was repeated two more times and the extract was pooled and evaporated to dryness under argon.

\subsubsection{Brain Extraction for Carotenoids}

Brain carotenoids were extracted according to the method of Vishwanathan et al. [22]. Brain samples (0.15 g) were homogenized (Power Gen 500, Fisher-Scientific, Hampton, NH, USA) with $0.3 \mathrm{~mL}$ of $0.9 \% \mathrm{NaCl}$ solution and $0.5 \mathrm{~mL}$ ethanol. Echinenone (100 $\mathrm{ng}$ ) dissolved in methanol as an internal standard and $2 \mathrm{~mL}$ ethanol were added to the homogenate. The mixture was vortexed vigorously for $2 \mathrm{~min}$ and the sides of the tube were scraped down. After incubating at $70^{\circ} \mathrm{C}$ for $2 \mathrm{~min}$, $0.5 \mathrm{~mL}$ of freshly-prepared $25 \%$ sodium ascorbate and $1 \mathrm{~mL}$ of $5 \% \mathrm{NaOH}$ were added. The mixture was saponified in a $60^{\circ} \mathrm{C}$ water bath for $20 \mathrm{~min}$. Subsequently, $0.5 \mathrm{~mL}$ of distilled water was added and the mixture was placed on ice for $5 \mathrm{~min}$. Five $\mathrm{mL}$ of hexane was added, and the mixture was vortexed for $2 \mathrm{~min}$ and centrifuged at $1000 \times g$ at $4{ }^{\circ} \mathrm{C}$ (Centrifuge CR3, Jouan, Winchester, VA, USA) for $10 \mathrm{~min}$. The upper hexane phase was removed and reserved. The hexane extraction process was repeated two more times. Hexane was pooled, dried using a Speedvac concentrator (model AS160; Savant, Milford, MA, USA), and evaporated to dryness under argon. Recovery of the internal standard averaged $80 \%$.

\subsubsection{Retinal Extraction for Carotenoids}

Retina carotenoids were extracted according to the method of Vishwanathan et al. [22]. The retinas were weighed and the tissue was ground with $1 \mathrm{~mL} 0.85 \%$ saline by using a glass rod on ice. To this, $3 \mathrm{~mL}$ chloroform-methanol $(2: 1, v / v)$ and $100 \mathrm{ng}$ echinenone (internal standard) in ethanol were added. After vortexing for $30 \mathrm{~s}$, the phases were separated by centrifugation at $800 \times g$ at $4{ }^{\circ} \mathrm{C}$ (Centrifuge CR3, Jouan) for $15 \mathrm{~min}$. The lower chloroform layer was transferred and evaporated to dryness under argon. The extraction was repeated using $3 \mathrm{~mL}$ hexane. The hexane layer was combined with the first extract and evaporated to dryness under argon. Recovery of the internal standard averaged $91 \%$.

\subsubsection{Adipose Tissue Extraction for Carotenoids}

Carotenoids were extracted from adipose tissues according to the method of Sy et al. [23]. Briefly, $125 \mathrm{mg}$ of adipose sample was weighed and homogenized (Power Gen 500, Fisher-Scientific) with $400 \mu \mathrm{L}$ Phosphate-buffered saline (PBS). Chloroform $(500 \mu \mathrm{L})$ and $1 \mathrm{~mL}$ methanol were added, followed by vortexing for $5 \mathrm{~min}$. After centrifugation at $1200 \times \mathrm{g}$ at $10{ }^{\circ} \mathrm{C}$ (Centrifuge CR3, Jouan) for 10 $\mathrm{min}$, the lower phase was collected and evaporated to dryness under argon. Ethanol-KOH $(1 \mathrm{~mL}$, $5.5 \%, m / v)$ and $100 \mu \mathrm{L}$ of freshly prepared ethanol-pyrogallol $(1.2 \%, m / v)$ were added to the dry residue and vortexed for $1 \mathrm{~min}$. The mixture was incubated at $37^{\circ} \mathrm{C}$ for $90 \mathrm{~min}$ for saponification. After incubation, $1 \mathrm{~mL}$ distilled water, $100 \mathrm{ng}$ echinenone dissolved in ethanol, and $3 \mathrm{~mL}$ hexane were 
added. Carotenoids were extracted by hexanes using the above-described steps. Recovery of the internal standard was $100 \%$.

\subsubsection{Extraction of Other Tissues for Carotenoids}

The extraction method used for other tissues has been previously described [24]. Samples were manually homogenized with ethanol containing $0.1 \% \mathrm{BHT}$, and $1 \mathrm{~mL}$ of saturated $\mathrm{KOH}$ solution was added. After saponification in a $60{ }^{\circ} \mathrm{C}$ water bath with intermittent vortexing for $30 \mathrm{~min}, 2 \mathrm{~mL}$ of deionized water and $6 \mathrm{~mL}$ of hexanes were added. Carotenoids were extracted by hexanes using the above-described steps.

\subsubsection{HPLC}

All analyses were carried out on an Alliance HPLC system (e2695 Separation Module) equipped with 2998 photodiode array detector (Waters, Milford, MA, USA). Sample extracts were reconstituted with $100 \mu \mathrm{L}$ of ethanol: methyl tert-butyl ether mixture $(1: 1, v / v)$ for brain, retina, and adipose tissue extracts or $40 \mu \mathrm{L}$ of mobile phase B for serum and the other tissues. The extracts were separated on a reverse-phase C 30 column $\left(4.6 \times 150 \mathrm{~mm}, 3 \mu \mathrm{m}\right.$; YMC, Wilmington, NC, USA) maintained at $18{ }^{\circ} \mathrm{C}$. A phase gradient method used for carotenoid separation was based on the method of Yeum et al. [25]. Carotenoids were identified via absorption spectra, retention times, and standard comparison and quantified by an external standard curve method or internal standard curve method. Figure 1 shows a HPLC chromatogram obtained from the serum extract of supplemented formula-fed monkey.

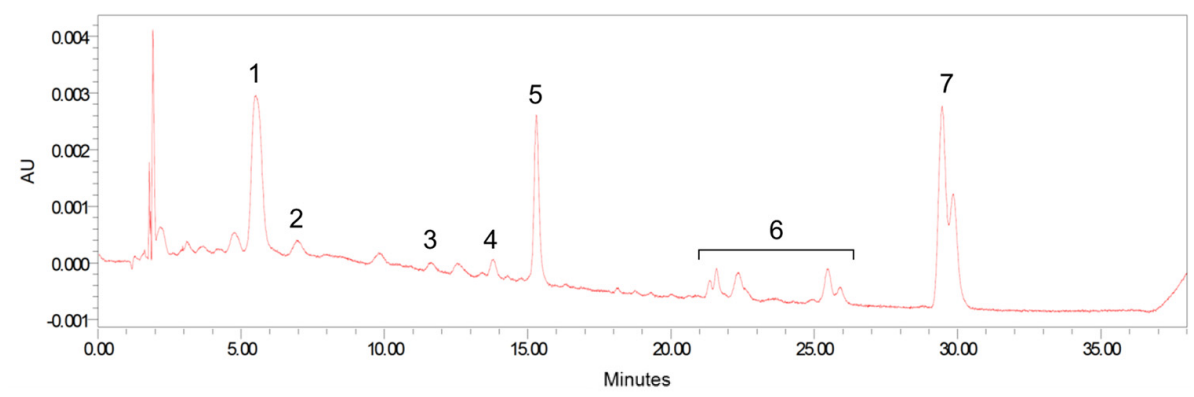

Figure 1. Representative high pressure liquid chromatography (HPLC) separation of carotenoids from serum. Peaks: 1 , lutein; 2 , zeaxanthin; 3 , $\beta$-cryptoxanthin; 4 , $\alpha$-carotene; 5 , $\beta$-carotene; 6 , cis-lycopene isomers; and 7, all-trans lycopene plus 5-cis lycopene

\subsection{Statistical Analysis}

All data were analyzed using SAS software version 9.3 (SAS Institute, Cary, NC, USA). Correlations between two variables were determined by Pearson's correlation coefficient.

\section{Results}

\subsection{Formula Carotenoids Profile, Formula Intake, and Body Weight}

The carotenoid profiles of the two formulas are presented in Table 1. The supplemented formula contained higher amounts of lutein and $\beta$-carotene (15-fold and three-fold, respectively), compared to the unsupplemented formula. Lycopene and zeaxanthin were present in the supplemented formula but were undetectable in the unsupplemented formula, while $\alpha$-carotene and $\beta$-cryptoxanthin were not detectable in either formula. Formula consumption ranged from 169 to $494 \mathrm{~mL} /$ day and increased with age and body weight (Figure 2). There were no consistent differences in formula intake or body weight between the two formula groups. 


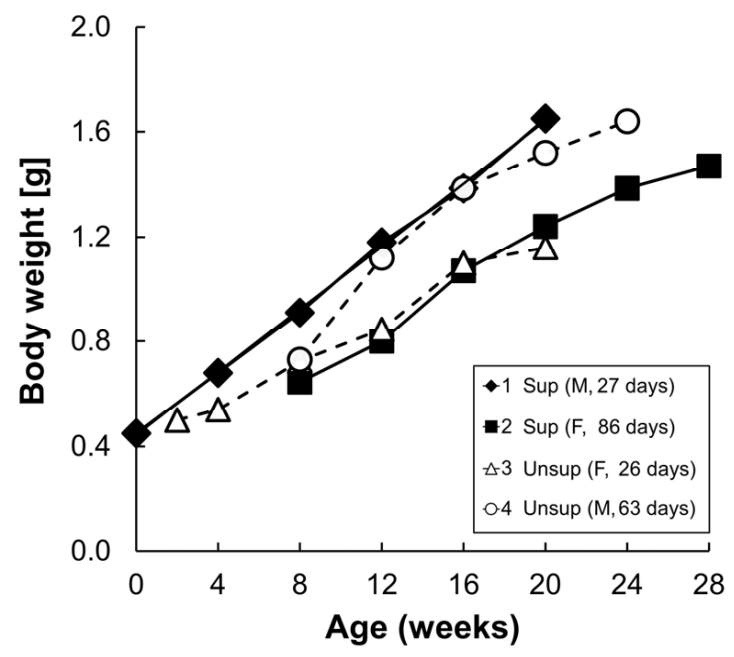

(a)

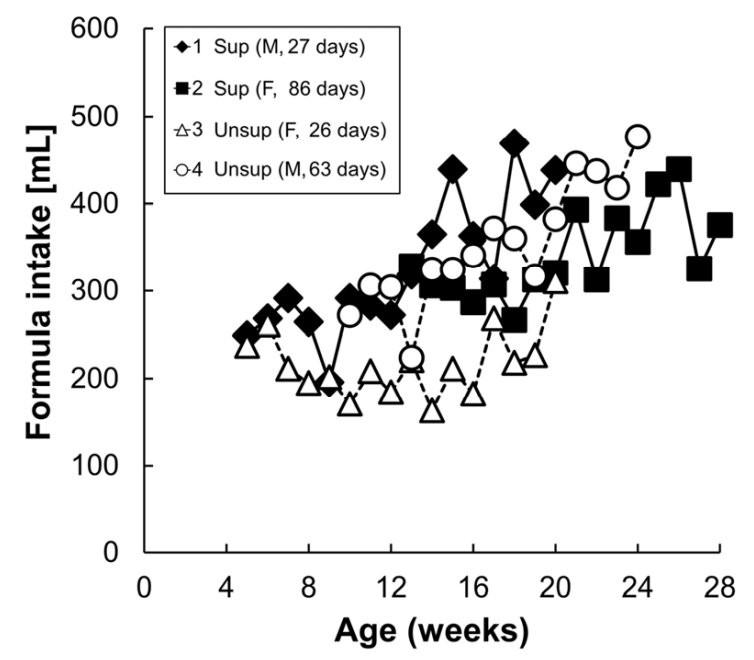

(b)

Figure 2. Body weight (a) of each infant monkey and daily formula intake consumed by infant monkeys (b) for 16 weeks. Each symbol represents one animal; solid symbol and solid line denote supplemented formula (Sup) while the open symbol and dotted line denote unsupplemented formula (Unsup).

\subsection{Plasma/Serum Carotenoids}

Figure 3 shows plasma/serum carotenoid concentrations at baseline, and following 2, 4, and 16 weeks of formula feeding. At baseline, $\beta$-cryptoxanthin, $\alpha$-carotene, $\beta$-carotene, lycopene, lutein, and zeaxanthin were detected in both groups, and the high baseline values are presumably largely due to the highly bioavailable carotenoid supply from breast milk [26]. In addition, the carotenoid levels at baseline were variable, perhaps due to variable breastmilk composition or intake. After 2-16 weeks of formula feeding, levels of all measured carotenoids decreased in the unsupplemented formula group. In the supplemented formula group, only serum lycopene levels increased at 16 weeks compared to their baseline values, due to the high concentration of lycopene in the supplemented formula (Figure 3a). Serum lutein concentrations decreased in both groups from baseline to four weeks on formula, but less so in the supplemented group; as a result, there was a three-fold difference in serum lutein levels between the two groups at 4 weeks (Figure 3b). By 16 weeks on supplemented formula feeding, serum lutein levels increased slightly from levels at four weeks, and were five times higher than in the unsupplemented group. Serum zeaxanthin levels dropped until four weeks of formula feeding in both groups (Figure 3c); they were undetectable in the serum of unsupplemented group by 16 weeks but were maintained in the supplemented group from four to 16 weeks. Serum $\beta$-carotene levels also were maintained in the supplemented group from four to 16 weeks and were two times higher than in the unsupplemented group by 16 weeks (Figure 3d). Plasma/serum $\alpha$-carotene and $\beta$-cryptoxanthin levels gradually decreased in both groups from baseline to 16 weeks since these two carotenoids were not present in the formulas (Figure 3e,f). 


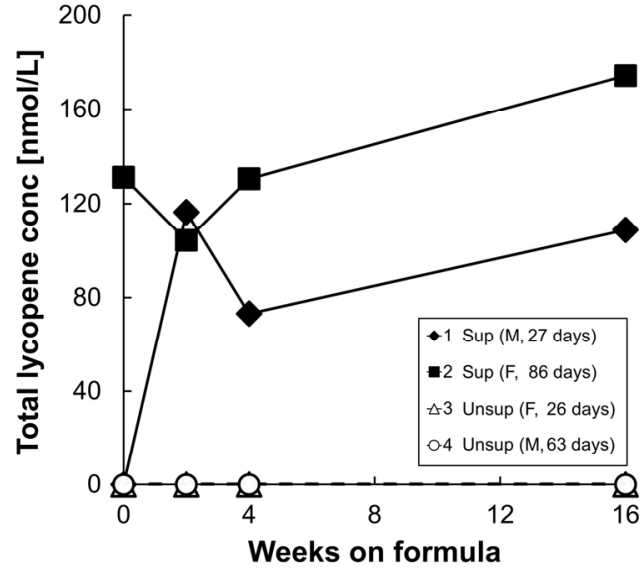

(a)

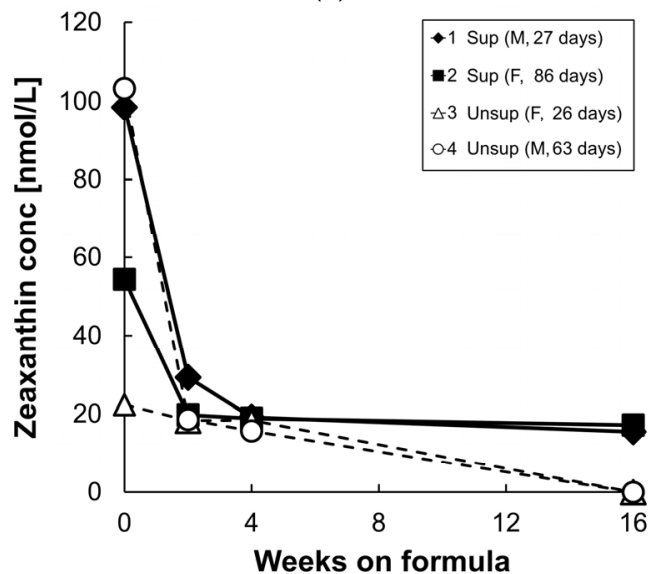

(c)

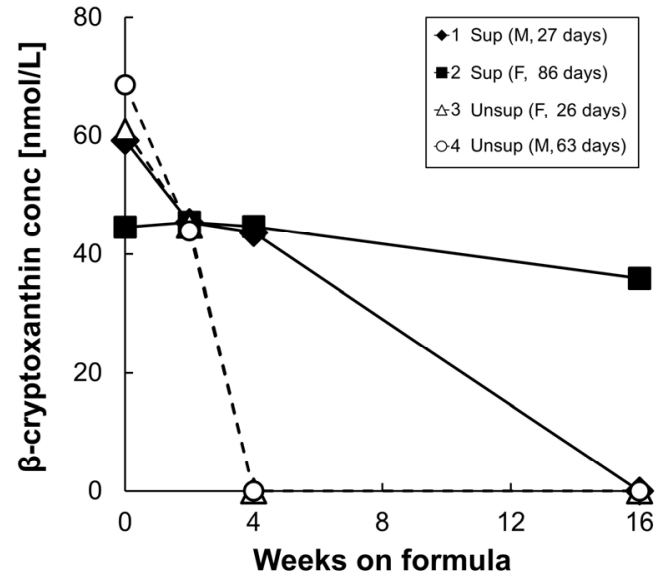

(e)

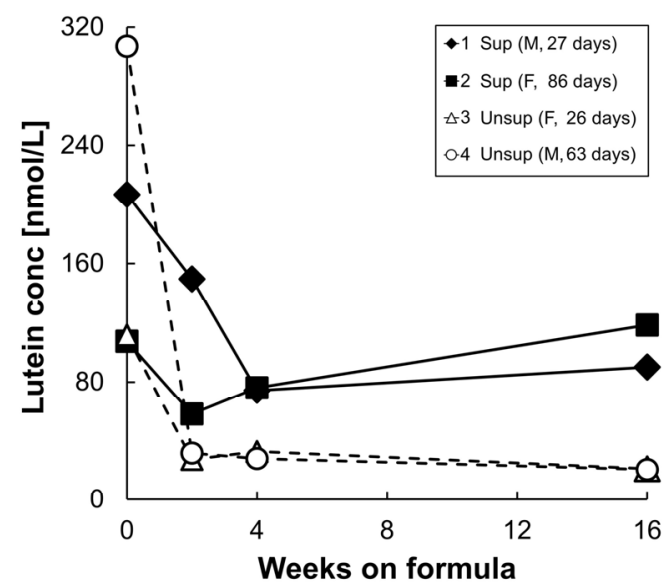

(b)

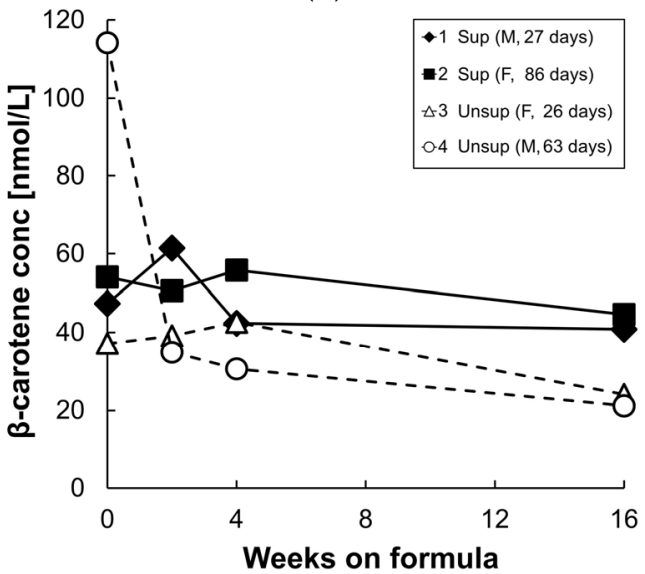

(d)

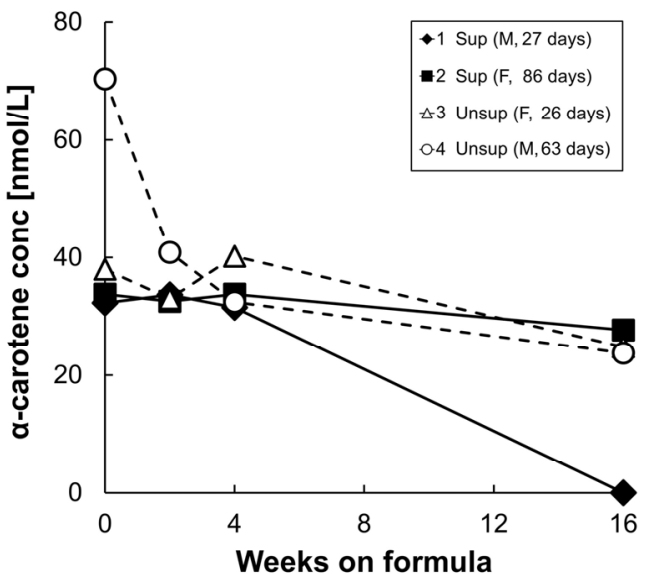

(f)

Figure 3. Plasma or serum total lycopene (a); lutein (b); zeaxanthin (c); $\beta$-carotene $(\mathbf{d}) ; \beta$-cryptoxanthin (e); and $\alpha$-carotene (f) concentrations of infant monkeys fed either supplemented formula $(n=2)$ or unsupplemented formula $(n=2)$ for 16 weeks. Each symbol represents one animal; solid symbol and solid line denote supplemented formula (Sup) while open symbol and dotted line denote unsupplemented formula (Unsup).

\subsection{Brain Carotenoids}

Lutein and $\beta$-carotene concentrations in the prefrontal cortex, occipital cortex, superior temporal cortex, striatum, cerebellum, and hippocampus after 16 weeks on infant formula are shown in Figure 4 . Lutein was differentially distributed across the six brain regions, with the highest concentration 
in the occipital cortex, regardless of the formula type. The supplemented formula resulted in a several-fold increase in lutein deposition in all brain regions compared to the unsupplemented formula. The lutein concentration in the supplemented group was three-fold higher in the occipital cortex and hippocampus (occipital: $64 \mathrm{pmol} / \mathrm{g}$ versus $21 \mathrm{pmol} / \mathrm{g}$; hippocampus: $30 \mathrm{pmol} / \mathrm{g}$ versus $10 \mathrm{pmol} / \mathrm{g}$ ) and six-fold higher in the striatum (32 pmol/g versus $5 \mathrm{pmol} / \mathrm{g}$ ) compared to that of the unsupplemented group. In contrast, in the monkeys fed unsupplemented formula, lutein was undetectable in the prefrontal and superior temporal cortices and cerebellum. Small amounts of $\beta$-carotene were detected (range: 0-23 pmol/g) across brain regions. Neither zeaxanthin nor lycopene were detected in any of the brain samples tested in either group. Lutein was the dominant carotenoid in all brain areas regardless of the formula type except for the superior temporal cortex, striatum, and cerebellum of the unsupplemented formula group in which lutein was undetectable or very low.

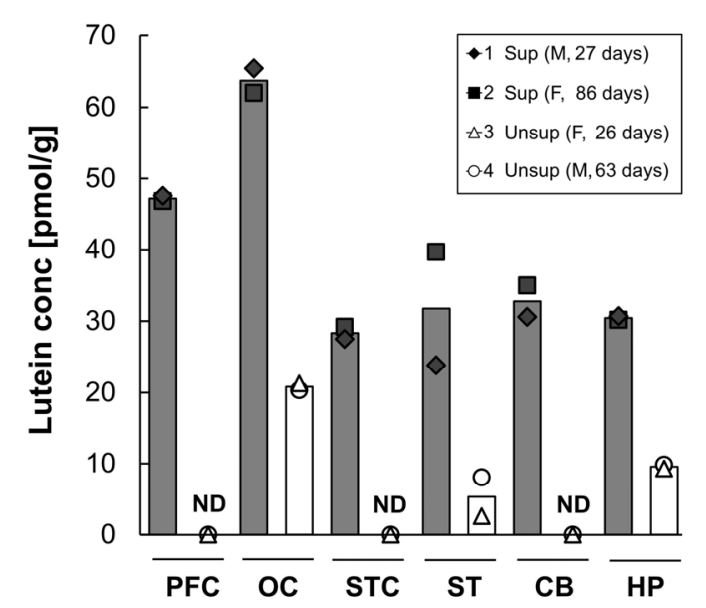

(a)

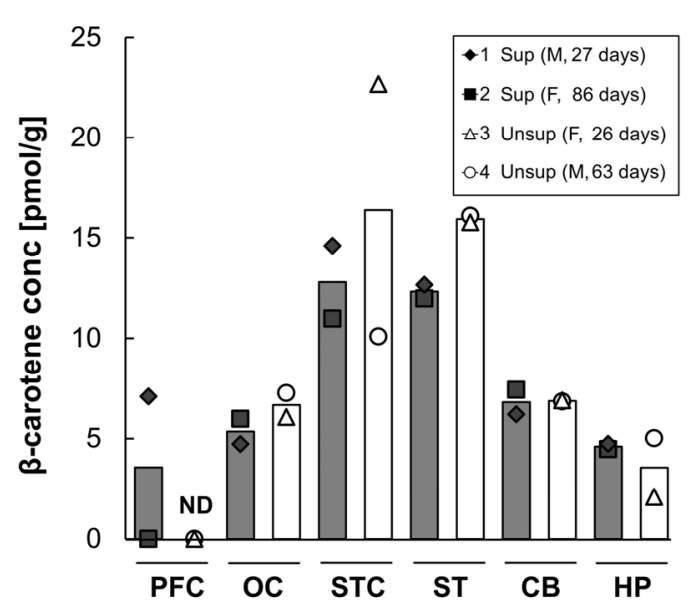

(b)

Figure 4. Lutein (a) and $\beta$-carotene (b) concentrations in each brain region of infant monkeys fed either supplemented formula $(n=2)$ or unsupplemented formula $(n=2)$ for 16 weeks. Each symbol represents individual animal; each column represents mean concentration of lutein of two animals. Solid column denotes supplemented formula (Sup) while open column denotes unsupplemented formula (Unsup). ND: not detected; PFC: prefrontal cortex; OC: occipital cortex; STC: superior temporal cortex; ST: striatum; CB: cerebellum; and HP: hippocampus

\subsection{Retinal Carotenoids}

Lutein and zeaxanthin concentrations in each retinal region are presented in Figure 5. As expected, lutein and zeaxanthin were present at high levels in the $4 \mathrm{~mm}$ diameter macular retina, whereas lower levels of lutein were present and no detectable zeaxanthin were present in peripheral retina. Mean lutein and zeaxanthin did not differ between formula groups in the $4 \mathrm{~mm}$ macular retina. However, in the peripheral retina, the mean lutein content was 2.5 times higher in supplemented monkeys $(196 \mathrm{pmol} / \mathrm{g})$ than in the unsupplemented group $(71 \mathrm{pmol} / \mathrm{g})$. $\beta$-Carotene, lycopene, $\beta$-cryptoxanthin, and $\alpha$-carotene were not detected in any of the retinal regions tested in either group.

Across all four subjects, serum lutein was strongly correlated with peripheral retina lutein $(r=0.98$, $p=0.02)$, but not with $4 \mathrm{~mm}$ macular retina lutein $(r=-0.09, p=0.91)$. 


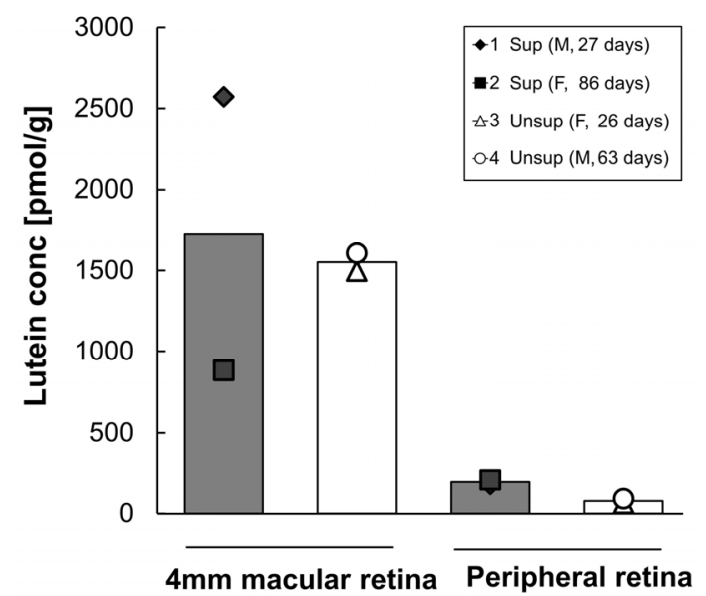

(a)

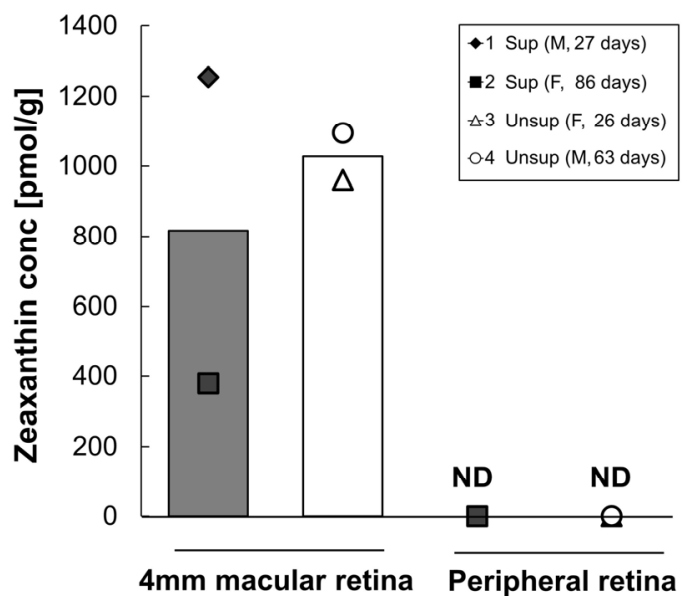

(b)

Figure 5. Lutein (a) and zeaxanthin (b) concentrations in each retina region of infant monkeys fed either supplemented formula $(n=2)$ or unsupplemented formula $(n=2)$ for 16 weeks. Each symbol represents individual animal; each column represents mean concentration of lutein of two animals. Solid column denotes supplemented formula (Sup) while open column denotes unsupplemented formula (Unsup). ND: not detected.

\subsection{Adipose Tissue Carotenoids}

Lutein, $\beta$-carotene, and lycopene concentrations in mesenteric (MAT), abdominal subcutaneous (ASAT), thigh subcutaneous (TSAT), and axillary brown adipose tissues (BAT) are shown in Table 3. Among the four different adipose areas, ASAT was the highest in lutein, regardless of the formula type. Lutein concentration was increased by supplemented formula in all adipose tissues analyzed, with approximately a three-fold increase in the ASAT (112 pmol/g versus $43 \mathrm{pmol} / \mathrm{g}$ ), a two-fold increase in the MAT (39 pmol/g versus $17 \mathrm{pmol} / \mathrm{g}$ ) and TSAT (88 pmol/g versus $39 \mathrm{pmol} / \mathrm{g}$ ), and a 13-fold increase in BAT (63 pmol/g versus $5 \mathrm{pmol} / \mathrm{g}$ ). Lycopene was not detectable in any adipose samples from the unsupplemented formula group, but was the predominant carotenoid in adipose tissues in the supplemented group. There were no consistent differences in $\beta$-carotene levels in adipose tissues between the groups.

Table 3. $\beta$-carotene, lutein, and total lycopene concentrations in each adipose region.

\begin{tabular}{|c|c|c|c|c|c|}
\hline \multirow{2}{*}{ Carotenoid } & \multirow{2}{*}{ Group, Animal ID } & MAT & ASAT & TSAT & BAT \\
\hline & & \multicolumn{4}{|c|}{ Mean (Individual Values), pmol/g } \\
\hline \multirow{2}{*}{$\beta$-carotene } & $\begin{array}{l}\text { Supplemented } \\
\qquad(1,2)\end{array}$ & $\begin{array}{c}77 \\
(49,105)\end{array}$ & $\begin{array}{c}125 \\
(91,159)\end{array}$ & $\begin{array}{c}56 \\
(68,45)\end{array}$ & $\begin{array}{c}105 \\
(107,102)\end{array}$ \\
\hline & $\begin{array}{c}\text { Unsupplemented } \\
\qquad(3,4)\end{array}$ & $\begin{array}{c}82 \\
(61,103)\end{array}$ & $\begin{array}{c}83 \\
(32,133) \\
\end{array}$ & $\begin{array}{c}100 \\
(131,68)\end{array}$ & $\begin{array}{c}59 \\
(43,75)\end{array}$ \\
\hline \multirow{2}{*}{ Lutein } & $\begin{array}{l}\text { Supplemented } \\
\qquad(1,2)\end{array}$ & $\begin{array}{c}39 \\
(25,53)\end{array}$ & $\begin{array}{c}112 \\
(71,154)\end{array}$ & $\begin{array}{c}88 \\
(69,107)\end{array}$ & $\begin{array}{c}63 \\
(78,47)\end{array}$ \\
\hline & $\begin{array}{l}\text { Unsupplemented } \\
\qquad(3,4)\end{array}$ & $\begin{array}{c}17 \\
(13,21)\end{array}$ & $\begin{array}{c}43 \\
(35,52)\end{array}$ & $\begin{array}{c}39 \\
(34,43)\end{array}$ & $\begin{array}{c}5 \\
(\mathrm{ND}, 10)\end{array}$ \\
\hline \multirow{2}{*}{ Total lycopene } & $\begin{array}{c}\text { Supplemented } \\
(1,2)\end{array}$ & $\begin{array}{c}227 \\
(162,291)\end{array}$ & $\begin{array}{c}391 \\
(280,502)\end{array}$ & $\begin{array}{c}350 \\
(220,481)\end{array}$ & $\begin{array}{c}333 \\
(295,371)\end{array}$ \\
\hline & $\begin{array}{c}\text { Unsupplemented } \\
\qquad(3,4)\end{array}$ & $\mathrm{ND}^{1}$ & ND & ND & ND \\
\hline
\end{tabular}

MAT: mesenteric adipose tissue; ASAT: abdominal subcutaneous adipose tissue; TSAT: thigh subcutaneous adipose tissue; BAT: brown adipose tissue. ${ }^{1} \mathrm{ND}$ : not detected. 


\subsection{Carotenoids in Other Tissues}

Table 4 shows the $\beta$-carotene, lutein, zeaxanthin, total lycopene, and $\alpha$-carotene concentrations in the liver, spleen, lung, kidney, heart, and quadriceps. Lutein was the predominant carotenoid in the liver of both groups. The greatest difference between the formula groups was found in the liver, with the supplemented group showing a nine-fold increase compared with the unsupplemented group, and higher levels in liver than in any of the other organs. Monkeys fed the supplemented formula also had increased lutein concentrations in the spleen, lung, kidney, heart, and quadriceps. However, in contrast to the supplemented group, in the unsupplemented group the lutein concentration of the liver was similar to that of spleen and lung. As in adipose tissues, lycopene was undetectable in the liver, spleen, lung, kidney, heart, and quadriceps from the unsupplemented formula group, but present in all cases in the supplemented group. $\beta$-carotene was present in the liver, spleen, lung, kidney, heart, and quadriceps of both formula groups, with somewhat lower levels in the liver, heart and spleen of the unsupplemented group. Zeaxanthin and $\alpha$-carotene were detectable only in the liver of the supplemented group, while $\beta$-cryptoxanthin was undetectable in all tissue samples.

Table 4. $\beta$-carotene, lutein, zeaxanthin, total lycopene, and $\alpha$-carotene, concentrations in liver, lung, kidney, heart, quadriceps, and spleen.

\begin{tabular}{|c|c|c|c|c|c|c|c|}
\hline \multirow{2}{*}{ Carotenoid } & \multirow{2}{*}{ Group (Animal ID) } & Liver & Lung & Kidney & Heart & Quadriceps & Spleen \\
\hline & & \multicolumn{6}{|c|}{ Mean (Individual Values), pmol/g } \\
\hline \multirow{2}{*}{$\beta$-carotene } & $\begin{array}{c}\text { Supplemented } \\
(1,2)\end{array}$ & $\begin{array}{c}56 \\
(51,61) \\
\end{array}$ & $\begin{array}{c}134 \\
(125,142)\end{array}$ & $\begin{array}{c}118 \\
(121,115)\end{array}$ & $\begin{array}{c}122 \\
(124,120)\end{array}$ & $\begin{array}{c}116 \\
(117,115)\end{array}$ & $\begin{array}{c}105 \\
(86,125) \\
\end{array}$ \\
\hline & $\begin{array}{c}\text { Unsupplemented } \\
\qquad(3,4)\end{array}$ & $\begin{array}{c}29 \\
(29,30)\end{array}$ & $\begin{array}{c}128 \\
(131,125)\end{array}$ & $\begin{array}{c}113 \\
(103,122)\end{array}$ & $\begin{array}{c}57 \\
(0,114)\end{array}$ & $\begin{array}{c}111 \\
(117,104)\end{array}$ & $\begin{array}{c}59 \\
(56,63)\end{array}$ \\
\hline \multirow{2}{*}{ Lutein } & $\begin{array}{c}\text { Supplemented } \\
(1,2)\end{array}$ & $\begin{array}{c}505 \\
(453,557)\end{array}$ & $\begin{array}{c}120 \\
(129,111)\end{array}$ & $\begin{array}{c}67 \\
(66,67)\end{array}$ & $\begin{array}{c}60 \\
(63,56)\end{array}$ & $\begin{array}{c}54 \\
(52,56)\end{array}$ & $\begin{array}{c}227 \\
(219,236)\end{array}$ \\
\hline & $\begin{array}{c}\text { Unsupplemented } \\
\qquad(3,4)\end{array}$ & $\begin{array}{c}59 \\
(54,63) \\
\end{array}$ & $\begin{array}{c}69 \\
(93,44) \\
\end{array}$ & $\begin{array}{c}35 \\
(30,39)\end{array}$ & $\begin{array}{c}35 \\
(34,35)\end{array}$ & $\begin{array}{c}34 \\
(37,31)\end{array}$ & $\begin{array}{c}67 \\
(71,63) \\
\end{array}$ \\
\hline \multirow{2}{*}{ Zeaxanthin } & $\begin{array}{c}\text { Supplemented } \\
(1,2)\end{array}$ & $\begin{array}{c}34 \\
(33,35)\end{array}$ & $\mathrm{ND}^{1}$ & ND & ND & ND & ND \\
\hline & $\begin{array}{c}\text { Unsupplemented } \\
\qquad(3,4)\end{array}$ & ND & ND & ND & ND & ND & ND \\
\hline \multirow{2}{*}{ Total lycopene } & $\begin{array}{l}\text { Supplemented } \\
\qquad(1,2)\end{array}$ & $\begin{array}{c}376 \\
(253,500)\end{array}$ & $\begin{array}{c}209 \\
(174,243)\end{array}$ & $\begin{array}{c}183 \\
(167,198)\end{array}$ & $\begin{array}{c}148 \\
(134,161)\end{array}$ & $\begin{array}{c}150 \\
(105,194)\end{array}$ & $\begin{array}{c}278 \\
(139,418)\end{array}$ \\
\hline & $\begin{array}{l}\text { Unsupplemented } \\
\qquad(3,4)\end{array}$ & ND & ND & ND & ND & ND & ND \\
\hline \multirow{2}{*}{$\alpha$-carotene } & $\begin{array}{l}\text { Supplemented } \\
(1,2)\end{array}$ & $\begin{array}{c}18 \\
(\mathrm{ND}, 35)\end{array}$ & ND & ND & ND & ND & ND \\
\hline & $\begin{array}{c}\text { Unsupplemented } \\
(3,4)\end{array}$ & $\begin{array}{c}34 \\
(33,35)\end{array}$ & ND & ND & ND & ND & ND \\
\hline
\end{tabular}

\section{Discussion}

Among dietary carotenoids, lutein is preferentially deposited in the human infant brain and retina, a finding that suggests a role in the development of these tissues [13,22]. Although lutein has been supplemented in some commercial infant formulas, its bioaccumulation pattern is not well understood in early life stages. This pilot study is the first report to describe lutein bioaccumulation patterns in nonhuman primate infants fed infant formulas with high or low levels of carotenoids.

Interest in the potential role of lutein in brain development has been prompted by studies showing that this carotenoid is selectively accumulated in the brain of infants, as well as adults [6,7]. A primary finding of the current study was that four months of feeding a carotenoid supplemented formula led to higher concentrations of lutein in all brain regions tested. We also determined that lutein accumulated differentially across brain areas. Lutein accumulation was highest in the occipital cortex, 
the primary visual processing area, which is consistent with an earlier report on brain carotenoids in xanthophyll-free adult monkeys fed pure lutein [22]. In contrast, in human tissue, the highest lutein accumulation was found in the cerebellum of centenarians [6] and in the auditory cortex of infants [7]. This suggests that lutein's accumulation across brain regions might differ between species and/or across the lifespan. While serum levels and ratios of carotenoids largely reflected their levels in the two formulas, in the infant brain the supplemented formula resulted in a specific and selective increase in lutein, with only small amounts of $\beta$-carotene and undetectable levels of the other carotenoids despite enhanced intake. Notably, we found that lutein was undetectable in prefrontal and superior temporal cortices and cerebellum of the unsupplemented formula group. This might suggest differences in the turnover rate of lutein across brain regions. Yonekura et al. showed different half-lives of lutein metabolites in multiple tissues of male mice as follows: plasma $<$ liver $<$ kidney $<<$ adipose tissues [27].

It is interesting to note that lutein concentration in the lutein-supplemented group was increased in the peripheral retina, but not in the $4 \mathrm{~mm}$ macular retina. We also observed a correlation between serum lutein and peripheral retina lutein, but not between serum lutein and macular retina lutein. One possible explanation is that lutein was preferentially deposited in the macular region in the first few weeks of life, prior to the initiation of formula feeding, whereas lutein in the peripheral retina continued to increase over the next four months in the supplemented group. Johnson et al. previously showed that lutein in both foveal and peripheral retina was increased by a high level of lutein supplementation in adult monkeys initially devoid of xanthophylls [28]. Many human clinical studies show that 2.4-30 mg of daily lutein supplementation enhances macular xanthophyll levels, as measured by MPOD, in healthy adults and in subjects with retinal diseases [29-33]. Johnson et al. also showed that lutein supplementation increased MPOD at several eccentricities in older women [34]. However, little is known about differential lutein deposition in the macular and peripheral retina, particularly in early life. These findings might be an important consideration when measuring MPOD in children, as several methods for measuring MPOD are based on comparing foveal to more peripheral retinal locations with regard to the relative absorption of short wavelength blue light, strongly absorbed by lutein and zeaxanthin, to middle wavelength light that is minimally absorbed [35].

Interestingly, we observed that lycopene, a non-hydroxylated carotene transported mainly by low-density lipoprotein (LDL) [36,37], was not found in any brain or retinal region. This lack of brain lycopene agrees with findings for the brains of human infants [7], whereas small amounts of lycopene (four-fold less than lutein) were found in the brain of centenarians [6]. As shown in Tables 3 and 4 , lycopene is readily taken up in body tissues of infant monkeys. Lutein, a polar hydroxylated carotenoid, is primarily transported by high-density lipoprotein (HDL) and to a lesser extent by LDL in the circulation [38]. In the retina, lutein is taken up via a scavenger receptor class B type I (SR-BI)-dependent mechanism [39], and protected by binding to a specific lutein binding protein, steroidogenic acute regulatory domain protein 3 (StARD3) [40]. Recent findings showed that lutein concentrations are related to levels of this protein in human brain [41], and that the relationship is particularly strong in the pediatric brain. Further study is required to determine the mechanism underlying preferential uptake of lutein, which may involve both HDL transport and StARD3.

It is also noteworthy that lutein's distribution is not homogenous among adipose depots. This result parallels a previous study showing site-specific lutein distribution in the subcutaneous adipose tissues in healthy human subjects [42]. One possible explanation for this regional lutein distribution is HDL metabolism. Transport by HDL may enhance lutein uptake into tissues. Despres et al. showed in obese patients that more HDL was taken up by subcutaneous adipocytes than omental adipocytes [43]. This difference may explain the higher lutein accumulation in subcutaneous adipose compared to visceral adipose. Furthermore, cholesteryl ester transfer protein is known to mediate selective uptake of HDL-cholesteryl ester in human adipocytes, and its mRNA expression is up-regulated in subcutaneous fat compared to visceral fat $[44,45]$. 
Lutein has both antioxidant and anti-inflammatory effects in vitro and in vivo. Considering that infants can be at special risk of oxidative stress, lutein's role as an antioxidant may be essential in early life. In an in vitro model of LPS-stimulated macrophages, lutein scavenged $\mathrm{H}_{2} \mathrm{O}_{2}$ and superoxide anions, decreasing the level of intracellular $\mathrm{H}_{2} \mathrm{O}_{2}$ accumulation and thereby inhibiting the NF- $\mathrm{kB}$ pathway [46]. Similarly, lutein treatment reduced the expression of inflammatory molecules by suppressing NF- $\mathrm{KB}$ activation in three types of cells associated with choroidal neovascularization [47]. Supplemental lutein prevented hypercholesterolemic diet-induced atherosclerosis in guinea pigs by decreasing malondialdehyde and oxidized-LDL [48]. In addition, lutein administration in the first hours of life increased biological antioxidant potential and decreased hydroperoxides compared to untreated human newborns who were exposed to oxidative stress [15]. Collectively, these earlier findings support the hypothesis that dietary lutein has a protective effect for many organs during early life.

\section{Conclusions}

In conclusion, in our small pilot study we found that increased early exposure to dietary lutein leads to enhancement of lutein tissue deposition. Notably, we found differential deposition of lutein in brain and adipose areas. Additional studies will be required to determine if lutein has a different half-life across different brain areas and other tissues and, more importantly, if lutein has a functional role in development of the brain, retina, and other organ systems.

Acknowledgments: This work was supported by a grant from Abbott Nutrition through the Center for Nutrition, Learning, and Memory (CNLM) at the University of Illinois at Urbana-Champaign, and by NIH grant P51011092. Publication costs were funded by CNLM. We are grateful to Molly Black who helped tissue carotenoid extractions and Emily Mohn who provided important advice for the brain carotenoid extractions.

Author Contributions: M.N., M.J.K., J.W.E. conceived and designed the experiments; S.J., M.N., E.E.J., E.J.J. performed the experiments; S.J., M.N., E.E.J., M.J.K., S.L.P., E.J.J., J.W.E. analyzed the data and wrote the paper.

Conflicts of Interest: This work was funded by Abbott Nutrition. Matthew J. Kuchan and Suzette L. Pereira are employed by Abbott Nutrition, as such, have affiliations with or financial involvement with Abbott Nutrition.

\section{References}

1. Sommerburg, O.; Keunen, J.E.; Bird, A.C.; van Kuijk, F.J. Fruits and vegetables that are sources for lutein and zeaxanthin: The macular pigment in human eyes. Br. J. Ophthalmol. 1998, 82, 907-910. [CrossRef] [PubMed]

2. Landrum, J.T.; Bone, R.A. Lutein, zeaxanthin, and the macular pigment. Arch. Biochem. Biophys. 2001, 385, 28-40. [CrossRef] [PubMed]

3. Koushan, K.; Rusovici, R.; Li, W.; Ferguson, L.; Chalam, K. The role of lutein in eye-related disease. Nutrients 2013, 5, 1823-1839. [CrossRef] [PubMed]

4. Leermakers, E.T.; Darweesh, S.K.; Baena, C.P.; Moreira, E.M.; Melo van Lent, D.; Tielemans, M.J.; Muka, T.; Vitezova, A.; Chowdhury, R.; Bramer, W.M.; et al. The effects of lutein on cardiometabolic health across the life course: A systematic review and meta-analysis. Am. J. Clin. Nutr. 2016, 103, 481-494. [CrossRef] [PubMed]

5. Johnson, E.J. Role of lutein and zeaxanthin in visual and cognitive function throughout the lifespan. Nutr. Rev. 2014, 72, 605-612. [CrossRef] [PubMed]

6. Johnson, E.J.; Vishwanathan, R.; Johnson, M.A.; Hausman, D.B.; Davey, A.; Scott, T.M.; Green, R.C.; Miller, L.S.; Gearing, M.; Woodard, J.; et al. Relationship between serum and brain carotenoids, alpha-tocopherol, and retinol concentrations and cognitive performance in the oldest old from the georgia centenarian study. J. Aging Res. 2013, 2013, 951786. [CrossRef] [PubMed]

7. Vishwanathan, R.; Kuchan, M.J.; Sen, S.; Johnson, E.J. Lutein and preterm infants with decreased concentrations of brain carotenoids. J. Pediatr. Gastroenterol. Nutr. 2014, 59, 659-665. [CrossRef] [PubMed]

8. Johnson, E.J.; McDonald, K.; Caldarella, S.M.; Chung, H.Y.; Troen, A.M.; Snodderly, D.M. Cognitive findings of an exploratory trial of docosahexaenoic acid and lutein supplementation in older women. Nutr. Neurosci. 2008, 11, 75-83. [CrossRef] [PubMed] 
9. Feeney, J.; Finucane, C.; Savva, G.M.; Cronin, H.; Beatty, S.; Nolan, J.M.; Kenny, R.A. Low macular pigment optical density is associated with lower cognitive performance in a large, population-based sample of older adults. Neurobiol. Aging 2013, 34, 2449-2456. [CrossRef] [PubMed]

10. Vishwanathan, R.; Iannaccone, A.; Scott, T.M.; Kritchevsky, S.B.; Jennings, B.J.; Carboni, G.; Forma, G.; Satterfield, S.; Harris, T.; Johnson, K.C.; et al. Macular pigment optical density is related to cognitive function in older people. Age Ageing 2014, 43, 271-275. [CrossRef] [PubMed]

11. Renzi, L.M.; Dengler, M.J.; Puente, A.; Miller, L.S.; Hammond, B.R., Jr. Relationships between macular pigment optical density and cognitive function in unimpaired and mildly cognitively impaired older adults. Neurobiol. Aging 2014, 35, 1695-1699. [CrossRef] [PubMed]

12. Yeum, K.J.; Ferland, G.; Patry, J.; Russell, R.M. Relationship of plasma carotenoids, retinol and tocopherols in mothers and newborn infants. J. Am. Coll. Nutr. 1998, 17, 442-447. [CrossRef] [PubMed]

13. Hammond, B.R., Jr. Possible role for dietary lutein and zeaxanthin in visual development. Nutr. Rev. 2008, 66, 695-702. [CrossRef] [PubMed]

14. Lieblein-Boff, J.C.; Johnson, E.J.; Kennedy, A.D.; Lai, C.S.; Kuchan, M.J. Exploratory metabolomic analyses reveal compounds correlated with lutein concentration in frontal cortex, hippocampus, and occipital cortex of human infant brain. PLoS ONE 2015, 10, e0136904. [CrossRef] [PubMed]

15. Perrone, S.; Tei, M.; Longini, M.; Santacroce, A.; Turrisi, G.; Proietti, F.; Felici, C.; Picardi, A.; Bazzini, F.; Vasarri, P.; et al. Lipid and protein oxidation in newborn infants after lutein administration. Oxidative Med. Cell. Longev. 2014, 2014, 781454. [CrossRef] [PubMed]

16. Erdman, J.W., Jr.; Smith, J.W.; Kuchan, M.J.; Mohn, E.S.; Johnson, E.J.; Rubakhin, S.S.; Wang, L.; Sweedler, J.V.; Neuringer, M. Lutein and brain function. Foods 2015, 4, 547-564. [CrossRef] [PubMed]

17. Li, B.; Vachali, P.P.; Gorusupudi, A.; Shen, Z.; Sharifzadeh, H.; Besch, B.M.; Nelson, K.; Horvath, M.M.; Frederick, J.M.; Baehr, W.; et al. Inactivity of human beta,beta-carotene- ${ }^{\prime}, 10^{\prime}$-dioxygenase (BCO2) underlies retinal accumulation of the human macular carotenoid pigment. Proc. Natl. Acad. Sci. USA 2014, 111, 10173-10178. [CrossRef] [PubMed]

18. Babino, D.; Palczewski, G.; Widjaja-Adhi, M.A.; Kiser, P.D.; Golczak, M.; von Lintig, J. Characterization of the role of beta-carotene 9,10-dioxygenase in macular pigment metabolism. J. Biol. Chem. 2015, 290, 24844-24857. [CrossRef] [PubMed]

19. Palczewski, G.; Amengual, J.; Hoppel, C.L.; von Lintig, J. Evidence for compartmentalization of mammalian carotenoid metabolism. FASEB J. 2014, 28, 4457-4469. [CrossRef] [PubMed]

20. Johnson, E.J.; Qin, J.; Krinsky, N.I.; Russell, R.M. Beta-carotene isomers in human serum, breast milk and buccal mucosa cells after continuous oral doses of all-trans and 9-cis beta-carotene. J. Nutr. 1997, 127, 1993-1999. [PubMed]

21. Nierenberg, D.W.; Nann, S.L. A method for determining concentrations of retinol, tocopherol, and five carotenoids in human plasma and tissue samples. Am. J. Clin Nutr. 1992, 56, 417-426. [PubMed]

22. Vishwanathan, R.; Neuringer, M.; Snodderly, D.M.; Schalch, W.; Johnson, E.J. Macular lutein and zeaxanthin are related to brain lutein and zeaxanthin in primates. Nutr. Neurosci. 2013, 16, 21-29. [CrossRef] [PubMed]

23. Sy, C.; Gleize, B.; Dangles, O.; Landrier, J.F.; Veyrat, C.C.; Borel, P. Effects of physicochemical properties of carotenoids on their bioaccessibility, intestinal cell uptake, and blood and tissue concentrations. Mol. Nutr. Food Res. 2012, 56, 1385-1397. [CrossRef] [PubMed]

24. Conlon, L.E.; King, R.D.; Moran, N.E.; Erdman, J.W., Jr. Coconut oil enhances tomato carotenoid tissue accumulation compared to safflower oil in the mongolian gerbil (meriones unguiculatus). J. Agric. Food Chem. 2012, 60, 8386-8394. [CrossRef] [PubMed]

25. Yeum, K.J.; Booth, S.L.; Sadowski, J.A.; Liu, C.; Tang, G.; Krinsky, N.I.; Russell, R.M. Human plasma carotenoid response to the ingestion of controlled diets high in fruits and vegetables. Am. J. Clin. Nutr. 1996, 64, 594-602. [PubMed]

26. Bettler, J.; Zimmer, J.P.; Neuringer, M.; DeRusso, P.A. Serum lutein concentrations in healthy term infants fed human milk or infant formula with lutein. Eur. J. Nutr. 2010, 49, 45-51. [CrossRef] [PubMed]

27. Yonekura, L.; Kobayashi, M.; Terasaki, M.; Nagao, A. Keto-carotenoids are the major metabolites of dietary lutein and fucoxanthin in mouse tissues. J. Nutr. 2010, 140, 1824-1831. [CrossRef] [PubMed] 
28. Johnson, E.J.; Neuringer, M.; Russell, R.M.; Schalch, W.; Snodderly, D.M. Nutritional manipulation of primate retinas, iii: Effects of lutein or zeaxanthin supplementation on adipose tissue and retina of xanthophyll-free monkeys. Investig. Ophthalmol. Vis. Sci. 2005, 46, 692-702. [CrossRef] [PubMed]

29. Bone, R.A.; Landrum, J.T.; Guerra, L.H.; Ruiz, C.A. Lutein and zeaxanthin dietary supplements raise macular pigment density and serum concentrations of these carotenoids in humans. J. Nutr. 2003, 133, 992-998. [PubMed]

30. Landrum, J.T.; Bone, R.A.; Joa, H.; Kilburn, M.D.; Moore, L.L.; Sprague, K.E. A one year study of the macular pigment: The effect of 140 days of a lutein supplement. Exp. Eye Res. 1997, 65, 57-62. [CrossRef] [PubMed]

31. Koh, H.H.; Murray, I.J.; Nolan, D.; Carden, D.; Feather, J.; Beatty, S. Plasma and macular responses to lutein supplement in subjects with and without age-related maculopathy: A pilot study. Exp. Eye Res. 2004, 79, 21-27. [CrossRef] [PubMed]

32. Duncan, J.L.; Aleman, T.S.; Gardner, L.M.; De Castro, E.; Marks, D.A.; Emmons, J.M.; Bieber, M.L.; Steinberg, J.D.; Bennett, J.; Stone, E.M.; et al. Macular pigment and lutein supplementation in choroideremia. Exp. Eye Res. 2002, 74, 371-381. [CrossRef] [PubMed]

33. Aleman, T.S.; Duncan, J.L.; Bieber, M.L.; de Castro, E.; Marks, D.A.; Gardner, L.M.; Steinberg, J.D.; Cideciyan, A.V.; Maguire, M.G.; Jacobson, S.G. Macular pigment and lutein supplementation in retinitis pigmentosa and usher syndrome. Investig. Ophthalmol. Vis. Sci. 2001, 42, 1873-1881.

34. Johnson, E.J.; Chung, H.Y.; Caldarella, S.M.; Snodderly, D.M. The influence of supplemental lutein and docosahexaenoic acid on serum, lipoproteins, and macular pigmentation. Am. J. Clin. Nutr. 2008, 87, 1521-1529. [PubMed]

35. Bartlett, H.; Howells, O.; Eperjesi, F. The role of macular pigment assessment in clinical practice: A review. Clin. Exp. Optom. 2010, 93, 300-308. [CrossRef] [PubMed]

36. Goulinet, S.; Chapman, M.J. Plasma ldl and hdl subspecies are heterogenous in particle content of tocopherols and oxygenated and hydrocarbon carotenoids. Relevance to oxidative resistance and atherogenesis. Arterioscler. Thromb. Vasc. Biol. 1997, 17, 786-796. [CrossRef] [PubMed]

37. Romanchik, J.E.; Morel, D.W.; Harrison, E.H. Distributions of carotenoids and alpha-tocopherol among lipoproteins do not change when human plasma is incubated in vitro. J. Nutr. 1995, 125, 2610-2617. [PubMed]

38. Wang, W.; Connor, S.L.; Johnson, E.J.; Klein, M.L.; Hughes, S.; Connor, W.E. Effect of dietary lutein and zeaxanthin on plasma carotenoids and their transport in lipoproteins in age-related macular degeneration. Am. J. Clin. Nutr. 2007, 85, 762-769. [PubMed]

39. During, A.; Doraiswamy, S.; Harrison, E.H. Xanthophylls are preferentially taken up compared with beta-carotene by retinal cells via a srbi-dependent mechanism. J. Lipid Res. 2008, 49, 1715-1724. [CrossRef] [PubMed]

40. Li, B.; Vachali, P.; Frederick, J.M.; Bernstein, P.S. Identification of stard3 as a lutein-binding protein in the macula of the primate retina. Biochemistry 2011, 50, 2541-2549. [CrossRef] [PubMed]

41. Tanprasertsuk, J.; Li, B.; Bernstein, P.S.; Vishwanathan, R.; Johnson, M.A.; Poon, L.; Johnson, E.J. Relationship between concentrations of lutein and stard 3 among pediatric and geriatric human brain tissue. PLoS ONE 2016, 11, e0155488.

42. Chung, H.Y.; Ferreira, A.L.; Epstein, S.; Paiva, S.A.; Castaneda-Sceppa, C.; Johnson, E.J. Site-specific concentrations of carotenoids in adipose tissue: Relations with dietary and serum carotenoid concentrations in healthy adults. Am. J. Clin. Nutr. 2009, 90, 533-539. [CrossRef] [PubMed]

43. Despres, J.P.; Fong, B.S.; Julien, P.; Jimenez, J.; Angel, A. Regional variation in HDL metabolism in human fat cells: Effect of cell size. Am. J. Physiol. 1987, 252, E654-E659. [PubMed]

44. Benoist, F.; Lau, P.; McDonnell, M.; Doelle, H.; Milne, R.; McPherson, R. Cholesteryl ester transfer protein mediates selective uptake of high density lipoprotein cholesteryl esters by human adipose tissue. J. Biol. Chem. 1997, 272, 23572-23577. [CrossRef] [PubMed]

45. Dusserre, E.; Moulin, P.; Vidal, H. Differences in mrna expression of the proteins secreted by the adipocytes in human subcutaneous and visceral adipose tissues. Biochim. Biophys. Acta 2000, 1500, 88-96. [CrossRef] 
46. Kim, J.H.; Na, H.J.; Kim, C.K.; Kim, J.Y.; Ha, K.S.; Lee, H.; Chung, H.T.; Kwon, H.J.; Kwon, Y.G.; Kim, Y.M. The non-provitamin A carotenoid, lutein, inhibits NF-kappaB-dependent gene expression through redox-based regulation of the phosphatidylinositol 3-kinase/PTEN/Akt and NF-kappaB-inducing kinase pathways: Role of $\mathrm{H}(2) \mathrm{O}(2)$ in NF-kappaB activation. Free Radic. Biol. Med. 2008, 45, 885-896. [CrossRef] [PubMed]

47. Izumi-Nagai, K.; Nagai, N.; Ohgami, K.; Satofuka, S.; Ozawa, Y.; Tsubota, K.; Umezawa, K.; Ohno, S.; Oike, Y.; Ishida, S. Macular pigment lutein is antiinflammatory in preventing choroidal neovascularization. Arterioscler. Thromb. Vasc. Biol. 2007, 27, 2555-2562. [CrossRef] [PubMed]

48. Kim, J.E.; Leite, J.O.; DeOgburn, R.; Smyth, J.A.; Clark, R.M.; Fernandez, M.L. A lutein-enriched diet prevents cholesterol accumulation and decreases oxidized LDL and inflammatory cytokines in the aorta of guinea pigs. J. Nutr. 2011, 141, 1458-1463. [CrossRef] [PubMed]

(C) 2017 by the authors; licensee MDPI, Basel, Switzerland. This article is an open access article distributed under the terms and conditions of the Creative Commons Attribution (CC-BY) license (http://creativecommons.org/licenses/by/4.0/). 